\title{
Study on the Aesthetic Significance of "Mourning Sorrow" in Japanese Literature
}

\section{Li Jiang}

Weinan Normal University, Weinan, Shaanxi, 714099

\author{
Keywords: Japanese Literature; "Mourning Sorrow"; aesthetic significance
}

\begin{abstract}
Sorrow" refers to the personal emotions that are intended to follow the heart and nature. From the bottom of the heart, people sigh at certain things. Through "I", they carefully taste "objects" to achieve people's subjective feelings, and emotional resonance with all things in the world. Actually, "sorrow" contains rich emotions, not just grief, but also personal emotions such as joy and anger. And "mourning" is full of exclamatory meaning, which is an innate emotional element and an aesthetic value orientation. As the mainstream aesthetic tendency of Japanese literature, "Mourning Sorrow" must be carefully scrutinized in a specific context. In Japanese literature, the spirit of "fate of grief" has risen to an aesthetic realm with some sort of character unity and natural expression. This kind of aesthetically oriented Japanese literature more or less reflects the meaning of "high purity". This paper mainly discusses the aesthetic significance of "Mourning Sorrow" in Japanese literature.
\end{abstract}

\section{Introduction}

"Genji Monogatari" is a representative work of Japan. Its main content exposes the contradiction between the ideal and the reality. The word "ai" can be seen everywhere, and you can appreciate the indifferent aesthetic taste of Japanese literature. Representing the "Genji Monogatari" as a representative, the "sugar mourning" in Japanese literature can be seen everywhere. The summary of its characteristics can be summarized as follows:

From the perspective of experientialism, the essence of "wuxi" is the subject's perception and experience of objective things. It is the projection of objective things on the subject's heart and emotions. The subject excites everything in the world by experiencing objective things and realizes Concrete to abstract emotional experience. For example, in the "Guan Guan Ju Guan", the poet sighed that "since the weak crown was from the king's affairs, and the wind and dust had never stopped", it was the natural expression of the author's true temperament and the direct expression of the beauty of "material mourning". Readers can feel the sadness and helplessness of the poet from the "weak crown" and "dust" and the sensitive perception of life and years, expressing the author's love for the momentary beauty of real life, and this slender and delicate emotional experience is A major feature of the "sadness".

Sadness" is a form of expression in which personal subjects and the world's objective things blend and place their feelings on objects. Japanese literature, however, cannot help but integrate the rich natural resources of Japan. The author's emotions are sent to nature's landscapes. Through the delicate brushstrokes that fully express the natural beauty of the landscape, readers will follow the author's description to appreciate the natural aura, and to experience the emotions the author wants to express through words. For example, the description of natural scenery in Huaifengzao is very common. For example, "the peach blossoms in the front of the palace and the wicker in the pond" are new. The peach and wicker create a fresh and mournful situation, reflecting the "sugar mourning" and the pursuit of the heart. The fusion of the aesthetic characteristics. In addition, in the Japanese literature, the description of the word "love" is very prominent. For instance, "Izu's dancing girl" and "breaking ring" which express male and female love are all expressions of love between men and women; " This kind of amorous love theme also reflects the feelings of tenderness and indescribable feelings. Not only is the love of men and women, the love between the two cats depicted in "I am the Cat" by Natsume Soseki, but also reflects the preference of Japanese writers 
for this theme.

The concept of "fate" originated from the Heian period and was formed in the "warm" Japanese language. The female aristocrats in the Heian era had an emotional experience with flowers and insects. Inspecting the origins of Japanese, the Japanese pseudonym was first created and used by women, and eventually developed into a mature language system in the modern sense. Therefore, the Japanese expression reflects the characteristics of affectiveness, profanity and fragmentation. Japan is rarely ambitious and has strict logic. In literary works, the corresponding "sadness" is affected by the expression of Japanese. The narrative space is often short and the narrative style is fragmented. The Fragmentation narrative features of the story works in the Heian period such as Utsuji Monogatari and The Story of the Past are very clear. Although the overall structure is relatively complete, the local description is still higher than the overall, and it is not the literary works of other countries that serve the whole part. And from the local narrative can also taste the unique taste of the work. In addition to story works, Japan's essay diary works are characterized by their fresh and elegant styles, such as "Tsaocaozi", "Tosa Diary", "Diary of Diary" and so on. It is also recorded as one thing. The text description is highly refined, and the style is elegant. The manifestation of the fragmented narrative form.

\section{The Formation of "Mourning Sorrow"}

Art comes from life and above life. Any literary works must be based on the times. Therefore, the spiritual characteristics of any literary works come from history, ethnicity, and even the natural and geographical environment. The concept of "worry" in Japanese literature This is also true, and the reasons for its formation can be summarized as follows:

As we all know, Japan is an island nation surrounded by the sea. The harsh natural environment has caused natural disasters to occur frequently. The people have formed a tenacious and unyielding character in the struggle against the natural environment. However, compared with the mysterious forces of nature, human power is insignificant. After all, people cannot overcome nature. The Japanese national character has a very good composition of victory. Once it is found that people cannot overcome nature, their psychological level will inevitably lead to a gap, and this drop will reflect a pessimistic mood in literary works. Therefore, works describing natural disasters in Japanese literature have attracted people's attention, such as earthquakes, volcanic eruptions, and storms. The theme of Haruki Murakami's "God's Children Can Dance" was taken from the earthquake. Komatsu Sasuke's "Japan" "Sink" is a famous disaster novel and so on. These literary works all depict natural disasters in detail. The readers are also influenced by the author's subtle influences. As time goes by, they will form a tendency of "sadness" and eventually become the main tone of Japanese literature.

Zen Buddhism exerted a tremendous influence on the development of Japanese cultural history. Japanese scholar Kato once said on Monday that "Zen was the result of the Muromachi period culture". In the middle of the sixth century, Japan had just started from the primitive social consciousness of myths and legends and all things, entered the period of formation of the social ideological system. At this time, the Buddha passed through Baekje to Japan and pursued the spiritual realm of loneliness, faintness, and seclusion, and Japanese culture. The development has had a profound influence. Zen philosophy has infiltrated Japanese tea ceremony, flowering, and calligraphy. Zen is not only elegant, indifferent, and mysterious. It is filled with a thin layer of sadness behind this kind of emotion. This kind of sadness is related to the impermanence of life, the disillusionment of life and death, and the passage of time. It sighs that life and death are separated. . Although the attitude of life is relatively negative, but it also allows people to keep a quiet moment in the turbulent world. The negative attitude towards life and the tranquility in the vicissitudes produced a kind of helplessness and pain in the present world. This kind of feeling is the mourning for things. The "things" in the "sad of things" include natural things, as well as the fickleness of life. As long as they are truly existing things, they can be called "materials". Only when they have real feelings about things that really exist, are they The real "worry".

His father, Fujiwara, was a famous Chinese literary scholar. Although his status was not high, he 
was good at song and Chinese poetry. Zizi learned Chinese literature at an early age and was familiar with Chinese books. There are more than 90 poems of Bai Juyi directly quoted in the "Source Story". Bai Juyi's works more deeply describe the living conditions of the working people in the middle and lower classes. Many poems have sad emotions, and this kind of features are sensitive to the Japanese. There are similarities and differences in the consciousness of "Mourning and Sadness". As the highest valued classical Chinese literary work "Genji Monogatari", it has an important influence on the formation of "Mourning Sorrow", in which the Sino-Japanese cultural exchanges and collisions affect the formation of the aesthetics of "Mourning Sorrow". It also has an important influence. In addition, the metaphysics of the Wei and Jin Dynasties in China also greatly influenced the generation of the ideological trend of the ancient "Wu-Lao" literature in the field of thought. The ideological framework of metaphysics in the Wei and Jin Dynasties was Lao Zhuang's thought. He believed that only by searching for the ontology of personality can one find the ontology of all things. Metaphysics also emphasizes the use of personality ontology to capture the universe. The metaphysics in the Wei and Jin Dynasties in China also influenced the formation and development of Chinese culture to a great extent. In the process of cultural exchanges between China and Japan, the metaphysics of the Wei and Jin Dynasties also exerted an indispensable influence on the formation of the aesthetics of the "material mourning".

\section{The Aesthetic Significance of "Mourning Sorrow" in Japanese Literature}

The beauty of "fate of mourning" pursued by Japanese literature is not simply to make words and sentences, but to generate emotional resonance through the works and readers, so that readers can produce a delicate reading experience in an intuitive and realistic world of experience. For example, the literary works of the Edo era were indifferent. Quiet quaint taste. "Sadness" is a complex emotional experience. The author expresses his true feelings through words from his own life experience. For example, in Fujiwara Yuhe's “Gifts and Judges”, there are words such as "stagnation" and "sentence", which can make people feel the lonely and lonely expression of emotions, and taste the life from the author's perspective. Another example is that in the "Pillow Grass", most of the captures are momentary feelings. The author starts with small things and micro-views, feels the taste with his soul, and then integrates his own feelings into his works. All of this stems from the emotional flow and reveals the author's natural emotions. Embodies a unique aesthetic taste.

Geographical factors have exerted an important influence on the formation of the aesthetic concept of "fear of things". Japan's natural geographical environment has made the Japanese people particularly sensitive to the changes of the four seasons, and at the same time has a strong feeling for the scenery of mountains and rivers of nature. There are also many works in Japanese classical literature that love to depict and extol the scenery of nature, and the natural changes of the four seasons are closely related to the genres of literary genres such as song and haiku. Japanese literati also have a special kind of affection for nature. This kind of natural and man-made realm makes people feel a harmonious beauty. For example, the types of works in "The Collection of Many Leaves" are divided according to the standards of the four seasons. The poets get their inspiration from the landscape and express their inner feelings, injecting new vitality into the songs and haikus.

"Mourning Sorrow" is an ethereal aesthetic realm. This realm can hardly be accurately described in terms of language. It can only describe some vague and ambiguous features. For example, the poet of the poet's service department has great clarity and far-reaching significance; for example, there is a vast window of the "Sichuan Chowder", which contains views about the southern Sichuan province of Kumamoto: The bells evoked Cuiwei, and the sand quarreled with the people and did not cross, and the white egrets reflected Jiang Fei". From the "Guanyin Pavilion" to the "Night Cloud" from the near and far, there were "bells" to "Egrets" from Jing Jing to the poems. The action creates a distant scene in the mind, which makes people appreciate the beauty of "a mournful thing". This kind of ambiguous beauty does not present things in a vague way, but is a form of expression of the beauty and is a scene. Perform artistic re-creation. Another example is Matsuo Basho's poem "Ancient Pond", which has a sentence of "Idle by the ancient pool, the frog leaping into the center 
of the pool, and the sound of water plops through it." The verse does not directly describe the natural world, but "frog" and "pound sound" Such dynamic images and voice images can allow readers to feel the vitality of the ancient pool.

\section{Conclusion}

In short, "Worry" is the aesthetic keynote of Japanese literature. It focuses on the psychological feelings and intuitive experience of the subject. It pursues a type of hidden bitterness, slenderness, and purely spiritual emotion. This kind of emotion is beyond reason. As an aesthetic category, "Mourning Sorrow" is not only the aesthetic pursuit of the Japanese national tradition, but also an aesthetic expression in life and art activities. It is the special ethnic environment and profound humanistic background that promote the formation of this aesthetic consciousness.

\section{References}

[1] Zhang Jin. Using Tragedy as Beauty—On the Material Sadness in Japanese Literature [J]. Foreign Language Studies, 2016(5): 172-174.

[2] Ye Ye. Using Tragedy as Beauty: Discussing the Sadness in Japanese Literature [J]. World Literature Review, 2012(1):229-232.

[3] Fang Aiping. On the Japanese people's aesthetic consciousness of "material mourning" [J]. Journal of Henan Polytechnic University Social Science Edition, 2006 (02): 31-33.

[4] Zhao Xiaoping, Lü Jiquan. On the Aesthetic Significance of "Mourning Sorrow" in Japanese Literature [J]. Journal of Xinxiang University (Social Science),2013(6):113-115.

[5] Wang Xiangyuan. Feelings of Sorrow: From the Perspective of Comparative Poetics, Discussing the Theory of "Mourning Sorrow" by Prof. Xuan Juechang[J]. Culture and Poetics, 2011(02): 102-105.

[6] Zhang Yi. On the Beauty of "Mourning Sorrow" in Kawabata Yasunari's Literature [J]. Literature Education (I), 2011 (7): 86-87. 